\title{
SOCIETAL CHANGE AND THE ECONOMICS OF FERTILITY AND FEMALE LABOUR FORCE PARTICIPATION
}

\author{
Jacques Poot and Jacques J. Siegers \\ Victoria University of Wellington and University of Utrecht
}

Most New Zealanders live in multi-person households. Despite a growing number of single-person households, the 1991 census showed that such people still account for only 8 percent of the population. The economic decisions which people in multi-person households take usually affect other members of the household. Thus the question emerges how decisions are made in households and how the effects of these decisions are distributed over household members. This is a complex issue but one which must be addressed, for example, to target social policies in a way which meets the needs of individuals. One area in which there is growing research interest is the impact of children in a household. Children affect the consumption patterns of households, saving behaviour, labour supply and, indeed, the decision to have more children. Browning (1992) provides a recent survey of these issues.

This paper reports the results of a New Zealand study of one aspect of household economics: the relationship between fertility behaviour and labour supply. Empirical research has shown that the presence of young children affects labour supply of the mother. New Zealand examples are Hyman (1979) and Harris and Raney (1991). However, Hockey and Khawaja (1984) found that a woman's labour force participation negatively affects fertility. In this paper we argue that fertility and labour force participation decisions are determined jointly rather than that there is a one-way causal relationship. We test this hypothesis by means of a simple regression model of fertility and female labour force participation using grouped data from 22 Local Government Regions (LGRs), pooled for the years 1976, 1981 and 1986. The next section discusses some of the theoretical issues. This is followed by a description of the data and a discussion of regression equations. After summing up the results, the last section provides some suggestions for further research.

\section{Theoretical Issues}

The notion that demographic phenomena can be studied within a standard neoclassical microeconomic framework was first made explicit by Becker's (1960) study of fertility. Becker interpreted, rather inelegantly, children as both durable consumption and production commodities and suggested that a higher income would lead to the demand for a higher quantity and quality of children, but with the income elasticity of quality exceeding that of quantity. Since empirical evidence often pointed to a negative relationship between income and fertility (e.g. Simon, 1974), this contradiction with the early theory was subsequently resolved by taking account of the fact that the raising of children and other household activities require time as well as money. In a sense, households "produce" final commodities (meals, recreation etc.) which require inputs of time and market goods (Becker, 1965). Increases in income raise the shadow price of time and may lead to a substitution away from time-intensive activities, among which is the rearing of children (e.g. Schultz, 1974). This idea can be applied to related questions of the division of labour within the household, marriage and other demographic phenomena and these issues have been fully explored in the "New Home Economics" (Becker, 1981; Cigno, 1991).

The traditional model of economic decisions in the "nuclear" family applies by no means to all households. The proportion of households which consist of a couple with one or more children dropped in New Zealand from 45.4 percent in 1971 to 28.8 percent in 1991 . However, including single parent and multiple family households, families with children accounted for about 45 percent of all households in 1991.

A full description of the standard microeconomic model of fertility and labour supply can be readily found in the literature (see e.g. Schultz, 1981; Poot and Siegers, 1992). Hence an informal outline will suffice here. The key idea is that a couple rationally plans to have a certain number of children and consume certain goods and services, subject to two constraints.

The first constraint is that the total time allocated to work, child care and leisure activities is limited by the total time available per day, excluding the time allocated to sleep, meals and personal care, which are less amenable to choice. However, some economists believe that people do make deliberate choices about the time spent on these basic human activities. For example, Biddle and Hamermesh (1990) show that higher wage rates reduce sleep time among men but increase their waking nonmarket time by an equal amount.

The second constraint is that total income can not exceed the sum of income earned from work and other income, such as interest received and social security benefits. The theory predicts that an increase in the hourly 
market wage which a woman can earn has two effects on the demand for children. The first is that for a given number of hours worked the higher wage provides a higher income and, hence, makes children more affordable. This "income effect" will imply a greater demand for children. However, the increase in the wage also makes the opportunity cost of time greater and would induce women to allocate less time to time-intensive activities, among which the rearing of children. Thus, this "substitution effect" reduces the demand for children. The net effect is uncertain, but given the status quo of (i) a higher wage being available to men than to women on average (e.g. Hyman, 1992a), and (ii) a disproportionate share of child care being provided by women, the theory predicts that an increase in the hourly wage for females will reduce the demand for children, increase the percentage of women in the labour force and also increase the hours worked by women in employment. The model of the allocation of time can also be used to show that an increase in the market income of the male partner, or an increase in other income, is likely to increase the demand for children and reduce the labour supply of the female.

It should be stressed that this is a very simple model which treats the demand for children no different from the demand for, say, watching television. It is therefore not surprising that the static neoclassical model has been criticised in the literature for providing an incomplete description of fertility behaviour. For example, economists have emphasised in recent years the need to consider decisions over the life cycle and transfers between generations (e.g. Becker and Barro, 1988; Tzannatos and Symons, 1989; Ehrlich and Lui, 1991). A more fundamental criticism focuses on the role of changes in the structure of society and the values system. Demographers and sociologists generally argue that the long-run transition to low fertility in developed countries is less associated with economic factors than with education, culture and a diffusion of values (e.g. Cleland and Wilson, 1987).

Another critique is put forward by feminist economists. The New Home Economics model assumes that the family is a unit within which adult members make informed and rational decisions that result in maximising the well being of the family. It is therefore not surprising that feminist economists, who emphasise power differences among partners in relationships and discrimination in the labour market, attach little explanatory power to the neoclassical approach (e.g. Hyman, 1992b). Obviously there are limits to the extent to which econometric analysis can capture such broad issues. Attempts to integrate economic and sociological approaches have tended to be difficult to model theoretically and verify empirically (Easterlin et al., 1980). Nonetheless, it is accepted that economic and social factors both contribute to a full explanation of the decline in fertility in Western economies since the 1960 s. For example, Pool (1992) points to the role of norms, values and ethnic diversity in fertility trends in New Zealand. Notwithstanding the value of non-orthodox and interdisciplinary approaches, in the present paper we shall restrict ourselves to hypotheses put forward in the literature which can be tested with readily available New Zealand data.

The first point to note is that the secular changes which have taken place in society, and which have led to a greater diversity in family structures and behaviour, may have affected the responsiveness of fertility and female labour force participation to changes in male income and the female wage. It can be shown that the elasticity of fertility with respect to the wage of the male or female in the household is a function of their respective shares of family income (Poot and Siegers, 1992). It is well known that female labour force participation has increased sharply in recent decades (e.g. Revell and Brosnan, 1986; Poot, 1988) and, hence, the female contribution to family income has increased. Moreover, fertility declined over the 197686 decade (Department of Statistics, 1989). Also, the contribution of males to housework and the care of children is expected to have increased. A New Zealand pilot survey (Department of Statistics, 1991) does not provide statistically useful information about this, but Juster and Stafford's (1991) survey reports a clear upward trend in the amount of time men devote to housework (routine chores, home projects and child care) in a range of developed countries. In addition, there has been a well known long-run increase in the substitutability between market commodities and time in home production (e.g. associated with the introduction of microwave ovens). However, if we consider the full range of household activities, the degree of substitutability between market goods and household time may have become relatively less in the care of children than in other activities (particularly chores such as cooking and cleaning), in which case the caring for children would become a relatively more time-intensive activity. This would suggest a declining income elasticity of the demand for children. These phenomena imply that the elasticities of female labour force participation and fertility with respect to male income and the female hourly wage can be expected to have become smaller in absolute terms over the 1976-86 decade. Finally, the changes in society which have made the "nuclear family" less representative of households generally may also reduce the role of the standard microeconomic variables. In the regression model we shall test this hypothesis by allowing for regression coefficients which may vary over time.

Another point to note that unemployment can affect the labour market attachment of individuals. Unemployment may generate the well known "added worker" and "discouraged worker" effects. The former refers to the increased participation of women of whom the spouse is unemployed or likely to become unemployment. The latter effect takes place when, in a slack labour market with a high unemployment rate, the cost of job search is high and the expected benefit of search is low. In that case some women will no longer be actively seeking work and female labour force participation declines. Although Rankin (1991) argues that the added worker effect has at 
times led to a considerable increase in female labour force participation in New Zealand, the consensus from the international literature is that the discouraged worker effect outweighs the added worker effect (see Hyman, 1979, pp. 116-117). The effect of the unemployment rate on labour force participation is therefore likely to be negative. The reduction in labour supply frees up time for children and we expect a positive effect of unemployment on fertility.

However, a contrary view arises when we introduce a distinction between a transitory and a permanent component of income. Transitory income is the difference between actual income and permanent income, which in turn is the expected return to labour market skills and financial wealth. A decline in transitory income is likely to lead to a postponement in the demand for children. Since the observational unit in the present paper is a region, median income of the regional labour force may be interpreted as a measure of permanent income, while the unemployment rate can serve as a proxy for a lack of transitory income. Following this argument, the effect of high unemployment on fertility is negative.

Another demand effect in the labour market is the sectoral composition. Despite the entry of some women into occupations regarded as "men's work", women and men in New Zealand are still largely segregated into quite separate occupations (Van Mourik et al., 1989). In 1986, 57 percent of women had clerical, sales or service occupations, compared with 22 percent of men. Hence, we expect that female labour force participation is higher in the regions where the demand for service sector workers is higher. Consequently, the effect of service sector employment on fertility is expected to be negative.

It is obvious that there can be a difference between the planned and actual number of children. Infertility may for some couples lead to an unsatisfied demand for children. At the same time, fertility control is not perfect. The literature suggests that the quality and effectiveness of contraceptives increases with the level of education of the woman (e.g. Michael, 1974). Moreover, greater participation of 15-24 year olds in fulltime education reduces fertility of this age-group. Hence, regions in which the population has an above average level of education are expected to have lower average fertility. Consequently, labour force participation will be higher in such regions, ceteris paribus. There may be four additional factors which may lead to a positive effect of education on participation. First, post-compulsory education is an investment in human capital which requires participation in paid work to reap the benefits. Second, the jobs available to the educated female may be relatively more attractive (interesting, creative) and yield positive utility. Third, the efficiency and effectiveness of job search are greater for those with higher levels of education. Fourth, education may lead to changing preferences and a more efficient "technology" of home making which induces women to substitute time at work for time at home.
Because we are using aggregate data for New Zealand regions to test these hypotheses, the composition of the population by marital status obviously affects total regional labour force participation and the average regional fertility rate. Given the increase in de facto relationships, nuptiality as measured by legal marriage may be an increasingly less useful indicator of fertility behaviour. We expect nonetheless that regions with a higher proportion of married women to have higher fertility and lower participation.

Ethnicity is likely to result in another composition effect. Despite the dramatic decline in Maori fertility during the last thirty years (e.g. Pool, 1991), the Maori Total Fertility Rate remained over the $1976-86$ period about 23 percent higher than for the total population (Department of Statistics, 1989). Thus, regions with a relatively greater proportion of the population of Maori descent are expected to have higher fertility and lower female labour force participation.

International studies have suggested that the demand for children is also affected by religious affiliation (see e.g. Hockey and Khawaja, 1984, p.8). Traditionally, practicing Roman Catholics tended to have higher fertility than non-Catholics, although in a New Zealand context this may no longer be significant. Our hypothesis is nonetheless that the regions with a disproportionately large number of Catholics would have higher fertility, all else being equal. The Roman Catholic proportion of the population remained relatively constant over the 1976 to 1986 period and varied between 22 percent in the West Coast LGR to 10 percent in Nelson Bays.

A final factor which we expect to have an impact on regional fertility and female labour force participation rates is the degree of urbanisation of a region. A more urbanised region is expected to be a region with lower fertility. One reason is that recent theories of economic growth show that the higher rate of growth of income per capita in urban areas would reduces the desired number of children (Becker and Barro, 1988). Moreover, children are also likely to be more expensive in urban areas. Schultz (1969) gives three reasons. First, the direct cost to feed and lodge a large family is likely to be higher in an urban area. Secondly, compared with the family farm there is less opportunity for urban children to be productive in a family business. Third, urban parents invest more in the education of their children. Thus, higher urbanisation is expected to reduce fertility and indirectly increase female labour force participation.

There are also direct positive effects of urbanisation on participation. First, females are segregated in occupations for which there are relatively more jobs in the larger urban areas. While this effect may be partly captured by taking account of the percentage of women in the services sector, there is also a greater supply of part-time and shiftworktype jobs in the larger urban areas. Second, there are also better child care facilities in the larger centres. Finally, a relatively large proportion of males in rural areas is 
employed in agriculture. While many of their spouses may carry out tasks on the farm, they may be counted in the census as persons carrying out "unpaid household duties" rather than being a "relative assisting unpaid". This reduces the measured labour force participation in rural areas. Hence, the degree of urbanisation is a final possible explanatory variable of fertility and labour force participation with a negative effect on the former and a positive effect on the latter.

\section{Data}

Previous research in New Zealand on fertility and female labour force participation has been hampered by a lack of data. Hyman (1979) examined the variation in female labour force participation across the Main Urban Areas in New Zealand in 1971. Her statistical inference was therefore based on 24 observations. More recent studies of female labour force participation are Ross (1987), who used a 1967/68 random sample survey of New Zealand women; Brooks (1991) who used Quarterly Employment Survey data; Harris and Raney (1991) and Harris (1992)who studied a cross-section of 1986 census data. All these authors considered fertility as exogenous. Hockey and Khawaja (1984) examined sub-national differentials in New Zealand fertility in 1976 using a range of definitions of regions, namely Local Government Administrative Regions (19), Main Urban Areas (24) and a type of rural regions (19). Hence, their analysis was based on a single cross-section of at most 24 observations.

To use a somewhat richer data base, we merged data from the 1976, 1981 and 1986 population censuses based on socio-economic characteristics of the 22 LGRs as they were defined in the early 1980s. Consequently, 66 observations were available. However, there have been a number of relatively minor differences in the questions and coding of the relevant census information. Such changes may affect the comparison of levels of variables across censuses and to ensure intertemporal consistency, all regional observations were standardised within each census file. Hence if $\mathbf{x}_{\text {irt }}$ refers to an observation for variable $i$ in region $r$ and census $t$, the regression model used $x^{*}{ }_{i r t}=\left(x_{i t}-m_{i t}\right) / s_{i t}$ where $m_{i t}$ and $s_{i t}$ are the mean and standard deviation respectively of variable $i$ across regions in census $\mathrm{t}$.

Published census data were mainly obtained from Lowe (1983, 1988) and Department of Statistics $(1982,1987)$. The endogenous variables are female labour force participation and fertility. When considering regional variations in participation, we must take account of the effect of age-composition since a cross-section of female labour force participation exhibits a well known and pronounced bi-modal age profile (e.g. Poot, 1988). Hence the participation variable (FLFPRT) is defined as the difference between the observed female labour force participation rate and the age-expected female labour force participation rate. The observed participation rate is the fraction of women aged $\mathbf{1 5}$ years and over who are in the labour force. The labour force consists of all females working one hour or more per week for pay, profit or as relative assisting, plus those actively seeking work. The age-expected regional participation rate is the aggregate participation rate which would result if age-group by agegroup the female labour force participation rate in a region would be identical to the corresponding national rate. The difference between the actual rate and the age-expected rate measures the regional variability in participation which cannot be attributed to age composition.

The FLFPRT observations are displayed in Figure 1. The value of FLFPRT in each region in the figure is the average over the three census years. The figure shows that, after controlling for differences in age composition, female labour force participation is atypically high in the Auckland and Wellington regions and very low in Aorangi. The theoretical discussion of the previous section suggests that a high degree of urbanisation of the Auckland and Wellington regions and a dominance of agriculture in Aorangi are contributing factors (see also Population Monitoring Group, 1989).

\section{Figure 1 Age-standardised female labour force} participation: regional deviation units

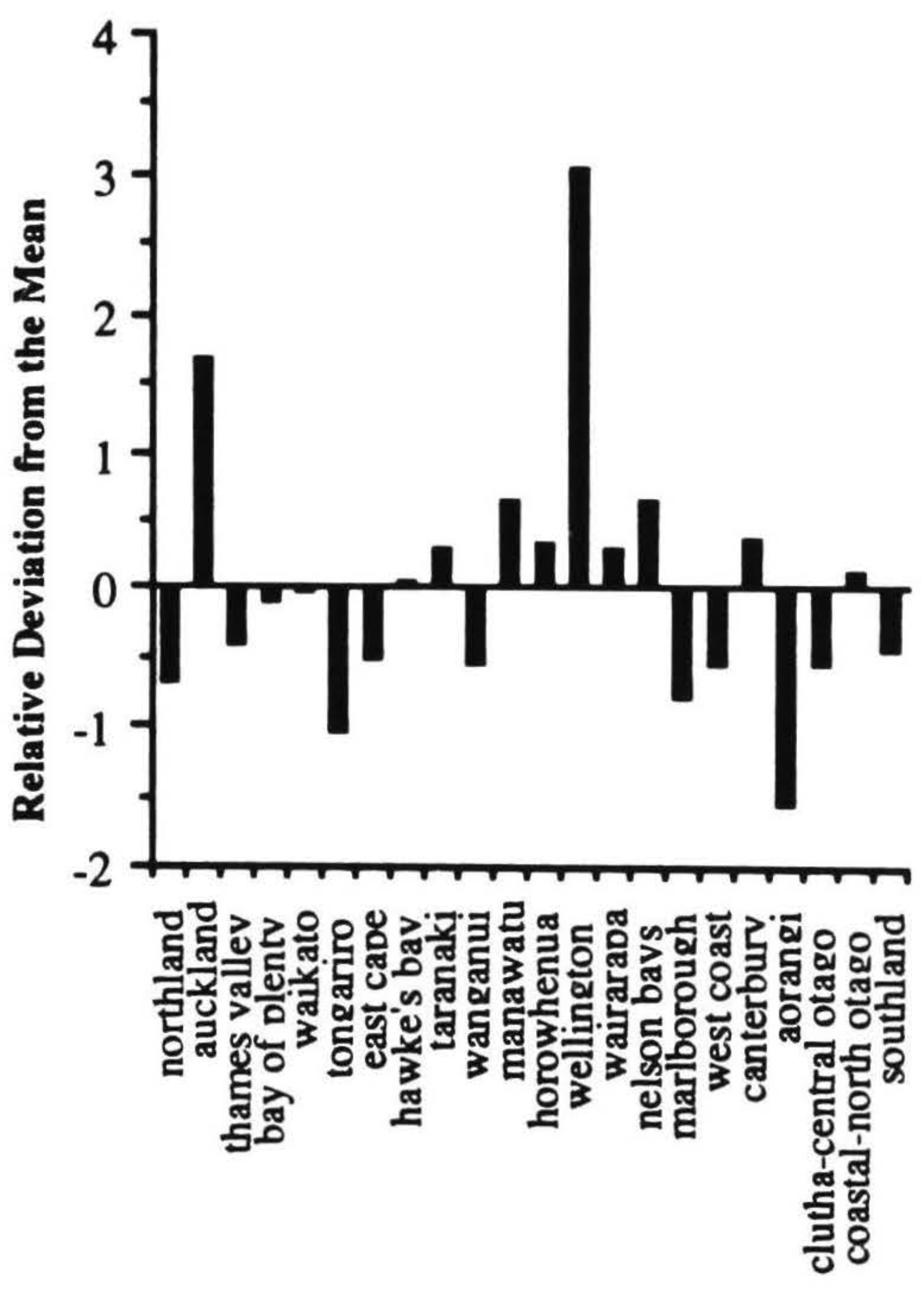

Region

Fertility is measured by the Total Fertility Rate (TFR). This is the average number of births a woman would have during her reproductive life if she was exposed to the fertility rates characteristic of various childbearing agegroups in a given year,i.e. the total fertility rate is the sum of the annual age-specific fertility rates. The variable 
FERTRT measures the regional average level of the TFR. The 1981 data were published in Department of Statistics (1989), while unpublished information was provided by the Department for 1976 and 1986. Figure 2 shows the regional variation in fertility rates.

\section{Figure 2 Total fertility rate: regional deviation units}

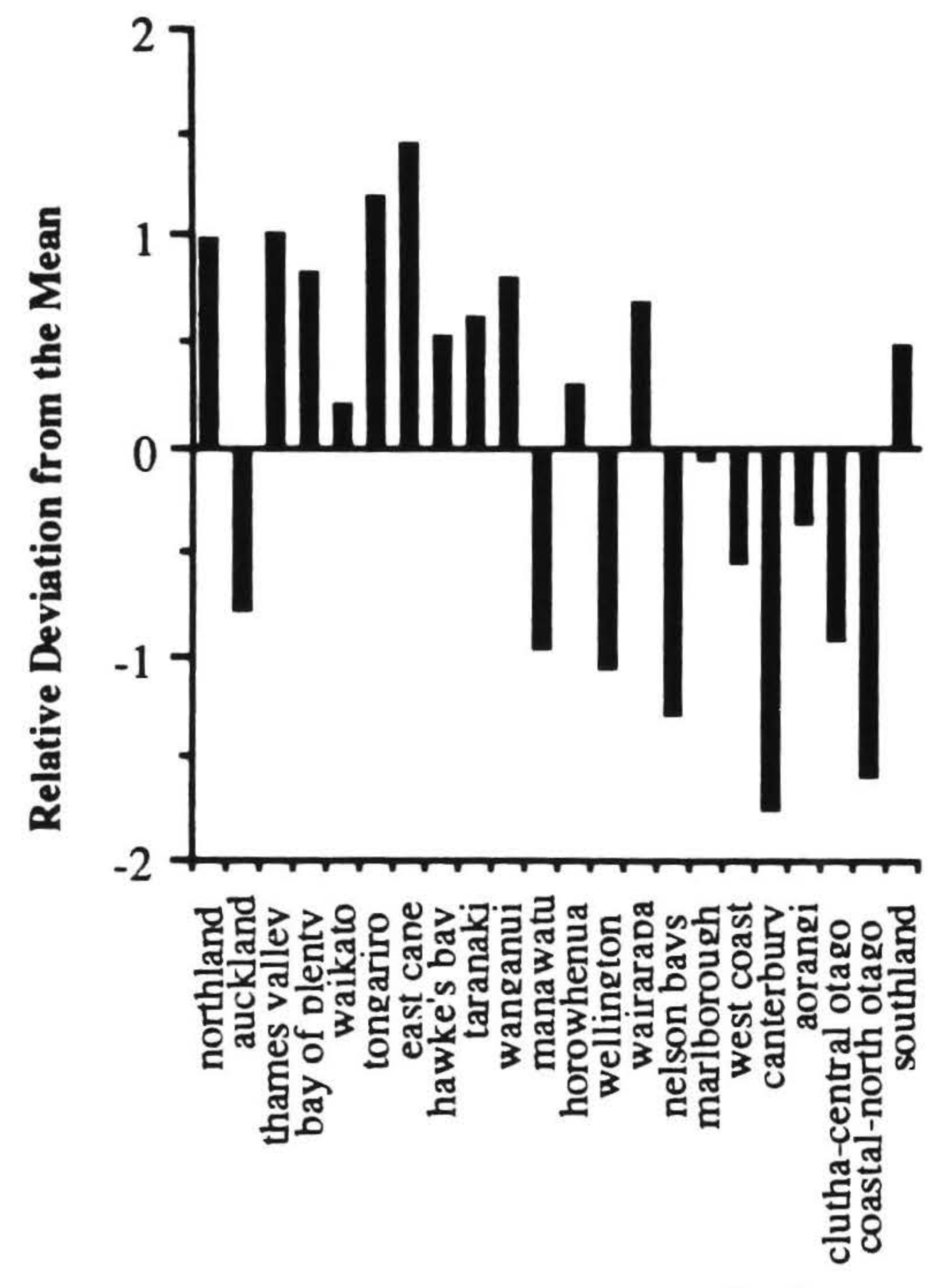

Region

Figure 2 shows that there are strong north-south differences in fertility in New Zealand. All South Island regions but Southland have below average fertility. This contrasts with the situation in the North Island where all but three regions have above average fertility. The exceptions are the highly urbanised regions of Auckland and Wellington, and Manawatu. These regional differences are partly a function of diverse childbearing patterns, which in turn reflect varied socio-economic and demographic circumstances such as ethnic composition, urbanisation, the economic situation and family-formation norms (see Population Monitoring Group, 1989). The regression model of the next section provides a more systematic and quantitative identification of the factors which have been responsible for the regional variation in female labour force participation and fertility.

\section{Results}

There are a number of econometric issues that must be addressed when we endeavour to test the theoretical reasoning of section 2 with the available regional data. A discussion of these issues is beyond the scope of the present paper, but full details can be found in Poot and Siegers (1992). Here we shall restrict ourselves to a discussion of two equations, one for female labour force participation and one for fertility. Both equations include all factors which we mentioned in section 2 . The estimation technique is Weighted Least Squares with weights equal to the square root of the regions' populations. The results are reported in Table 1.

Given the idea that child rearing and market work are competing uses of time, we noted earlier that it can be expected that variables which have a positive effect on female labour force participation have a negative effect on fertility and vice versa. Table 1 shows that this is indeed the case for nine out of the 13 variables considered. The reader may wonder whether the pattem of opposite signs is not simply the result of the dependent variables (FLFPRT and FERTRT) having a very close inverse relationship between them. However, Figure 3 shows that this is not the case. The simple correlation coefficient of the relationship between fertility and female labour force participation is only -0.419 for the 66 observations. Despite this, the factors which significantly influence female labour force participation affect fertility in the opposite way.

The exception is the unemployment rate (FUNEMR). A high rate of unemployment reduces female labour force participation (the discouraged worker effect). However, a high unemployment rate also reduces fertility. We noted in section 2 that this may be because the decline in income associated with unemployment may be seen as temporary, leading to a postponement of having children until these can again be "afforded".

Table 1 shows that an increase in the annual median income of males (MYMALE) reduces female labour force participation and increases fertility. However, an increase in the average hourly earnings of females employed fulltime (FEWAGE) increases participation and reduces fertility. It should be noted that we are ignoring here the possible endogeneity of the female wage in the participation equation. Since in the period under consideration national wage determination was still prevalent, it it unlikely that a regional variation in labour supply conditions would have had a marked impact on regional wages. Hence, considering the female wage as predetermined may be reasonable in the present context.

We suggested earlier that changes in the structure and norms of society may affect the responsiveness of fertility and labour force participation to the income and wage effects. The regression equations in Table 1 test if secular trends have affected the coefficients of MYMALE and FEWAGE in the participation and fertility equations. For example, when most women already participate, the income effect of an increase in the female wage becomes important. The substitution effect remains negative as long as children take up a relatively large proportion of the female's time. Hence we expect that the coefficient of FEWAGE in the fertility equation becomes less negative. Similarly, as women now supply a larger proportion of full 
Table 1 Regression equations

Dependent Variable FLFPRT

FERTRT

\begin{tabular}{|c|c|c|}
\hline MYMALE & $\begin{array}{l}-0.373 * * \\
(0.134)\end{array}$ & $\begin{array}{l}0.281^{*} \\
(0.133)\end{array}$ \\
\hline FEWAGE & $\begin{array}{l}1.101^{* *} \\
(0.124)\end{array}$ & $\begin{array}{c}-0.247^{*} \\
(0.123)\end{array}$ \\
\hline FUNEMR & $\begin{array}{l}-0.481^{* *} \\
(0.078)\end{array}$ & $\begin{array}{l}-0.255^{* *} \\
(0.077)\end{array}$ \\
\hline ESERVI & $\begin{array}{l}0.131 \\
(0.107)\end{array}$ & $\begin{array}{l}-0.227^{*} \\
(0.106)\end{array}$ \\
\hline TEREDU & $\begin{array}{l}-0.098 \\
(0.109)\end{array}$ & $\begin{array}{l}-0.215 \\
(0.109)\end{array}$ \\
\hline FNUPTI & $\begin{array}{l}0.032 \\
(0.106)\end{array}$ & $\begin{array}{l}0.220^{*} \\
(0.106)\end{array}$ \\
\hline MAORIR & $\begin{array}{l}0.033 \\
(0.085)\end{array}$ & $\begin{array}{l}0.914^{* *} \\
(0.084)\end{array}$ \\
\hline ROMCAT & $\begin{array}{l}-0.151^{*} \\
(0.076)\end{array}$ & $\begin{array}{l}0.254^{* *} \\
(0.075)\end{array}$ \\
\hline URBANI & $\begin{array}{l}0.286^{*} \\
(0.112)\end{array}$ & $\begin{array}{l}-0.010 \\
(0.111)\end{array}$ \\
\hline MYMA81 & $\begin{array}{l}0.131 \\
(0.159)\end{array}$ & $\begin{array}{l}-0.210 \\
(0.158)\end{array}$ \\
\hline MYMA86 & $\begin{array}{l}0.533^{*} \\
(0.204)\end{array}$ & $\begin{array}{l}-0.499^{*} \\
(0.203)\end{array}$ \\
\hline FEWA81 & $\begin{array}{l}-0.231 \\
(0.145)\end{array}$ & $\begin{array}{l}0.279 \\
(0.144)\end{array}$ \\
\hline FEWA86 & $\begin{array}{l}-0.619^{* *} \\
(0.187)\end{array}$ & $\begin{array}{l}0.473^{*} \\
(0.186)\end{array}$ \\
\hline \# of obs. & 66 & 66 \\
\hline $\mathrm{R}^{2}$ & 0.9435 & 0.9075 \\
\hline $\mathbf{s}$ & 0.3162 & 0.3141 \\
\hline
\end{tabular}

Note: Standard Errors in Parentheses

*: a < 0.05; **: a 0.01

Source: Poot and Siegers (1992), Table 2. income, the income effect of an increase in male income on fertility becomes less positive. The substitution effect, however, remains positive as long as men devote little time to their children. The coefficient of MYMALE in the FERTRT equation would consequently become smaller. We would expect similar trends, but in the opposite direction in the FLFPRT equation. The effects of introducing time-varying coefficients for MYMALE and FEWAGE are measured by means of the variables MYMA81, MYMA86, FEWA81 and FEWA86. These are obtained by interacting the variables MYMALE and FEWAGE with dummy variables for 1981 and 1986, which are equal to one in the year referred to and zero otherwise.

Table 1 shows that there has been indeed a change in the wage and income elasticities on fertility and female labour force participation. As expected, the change in the fertility equation is in the opposite direction of the change in the participation equation. The coefficient of MYMALE in the participation equation changes from -0.373 in 1976 to

-0.242 in 1981 (the coefficient of MYMA81 is the marginal change) and subsequently to +0.160 in 1986 . The own-wage effect of female labour force participation reduces to +0.870 in 1981 and +0.482 in 1986 . In the fertility equation, the coefficient of MYMALE changes to from 0.281 in 1976 to -0.218 in 1986 , via +0.071 in 1981 , and the coefficient of FEWAGE changes from -0.247 to +0.032 and subsequently to +0.226 . The change in 1986 is statistically significant in all cases.

What is puzzling is the apparent reversal of the sign of the coefficients in three of the four cases. Although the regression results are consistent with secular trends over time in the increasing participation of women, declining fertility and the more equal sharing of domestic duties, the magnitudes of such effects appear exaggerated by the model. Eventually, if men and women shared child care time equally and both worked equal hours, and the income elasticity for the demand for children is small, we would expect that the effect on the "price" of children of a change in the real wage outweighs the income effect and that rising real incomes and economic growth lead to a secular decline in fertility.

Considering now the remaining variables, the fract of the full-time labour force employed in service seci S (ESERVI) has a positive effect on female labour supply and a negative effect on fertility, although it is only statistically significant in the latter case. The fraction of the population that attended a form of post-secondary education (TEREDU) negatively affects fertility, although it just fails the 5 percent significance criterion. The clear insignificance of TEREDU in the participation equation may be due to the presence of FEWAGE, since education is an important component of human capital which determines the wage. However, at the macro level the two are only mildly correlated $(r=0.566)$. 


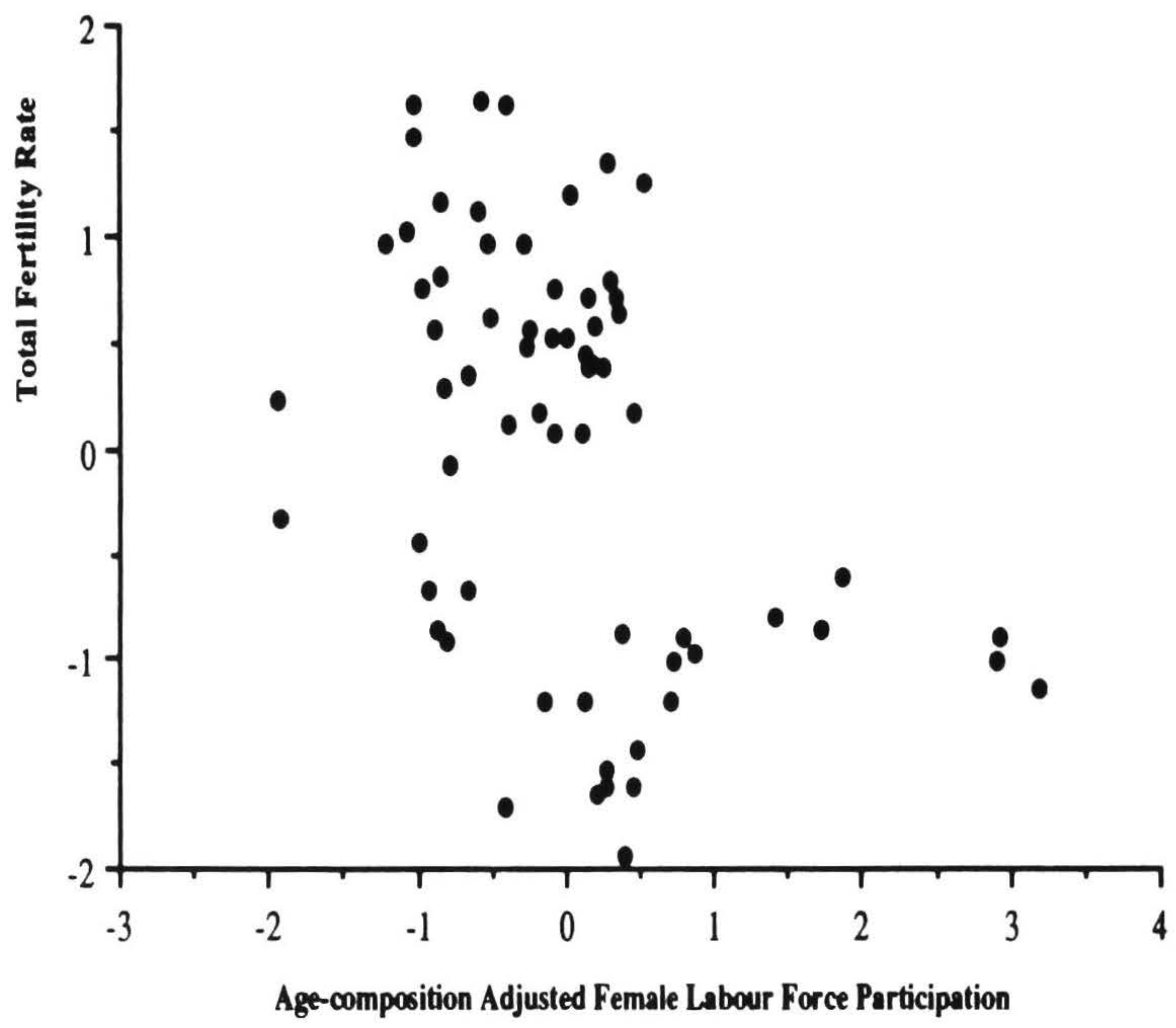

The fraction of women aged 15 years and over who are married (FNUPTI) does positively affect fertility, as does the fraction of the population that is half or more of Maori descent (MAORIR). An interesting variable is ROMCAT, the fraction of the population that is Roman Catholic. This variable is ignored in behavioural equations of labour force participation when its effect is assumed to have been captured by the fertility rate, but in our household economics model it is the former variable which should be included, not the latter. ROMCAT is indeed significant in both regression equations. Female labour force participation is also significantly greater in the more urbanised regions, as can be seen by the coefficient of URBANI (the fraction of the population living in municipalities of 10,000 people and over).

In contrast with earlier studies of female labour force participation, the FLFPRT equation in Table 1 does not include fertility or some other "young children present" variable among the regressors. Similarly, the FERTRT equation does not include female labour force participation as an explanatory variable. The reason for this is that the standard neoclassical model suggests that fertility and labour force participation are both influenced in opposite ways by a number of factors, without there being a direct causal relationship between the two. This possibility was supported by Mincer's (1962) work on the United States. Mincer found that male full-time income had a negative coefficient in a regression equation for female labour force participation, while (potential) full-time income of the female had a positive effect. The signs in the fertility equation were the opposite of those in the participation equation: positive for male income and negative for female potential income. Table 1 showed that this is also true in the New Zealand case. When adding labour force participation as an additional explanatory variable in the fertility equation, Mincer found that its coefficient was insignificant and concluded that there is no direct causal relationship between fertility and female labour force participation. Regression models reported in Poot and Siegers (1992) show that again the same is true in the New Zealand case. These results suggest that there is no "chicken or egg" problem and that Mincer's (1962) classic conclusion that fertility and labour force participation are inversely related because they are affected in opposite ways by the same economic variables, referred to recently by Browning (1992, p.1464) as the "purist approach", does appear to have some validity in the New Zealand context.

However, the view that fertility and labour supply decisions are part of a deterministic optimisation problem, in which a couple formulates once and for all at the beginning of their relationship an optimal consumption plan, is rather unrealistic. In theory, a stochastic dynamical perspective would be more plausible. In practice, participation is much easier adjusted to exogenous shocks than fertility. Desired fertility may be a control variable in an optimal consumption plan over the life cycle and actual fertility may be correlated with intentions, but there are unlikely to be smooth adjustments over time in response to exogenous shocks. In contrast, labour force participation does tend to be quite responsive to short-run labour market 
conditions. For example, labour shedding in New Zealand manufacturing in recent years has led to a predictable downward response in female labour force participation. If participation is more flexible than fertility behaviour, fertility may directly affect participation, but participation may not directly affect fertility.

Further speculation about causality in the relationship between fertility and female labour force participation is probably not very fruitful without an explicit dynamical approach in which it is clear what is to be considered predetermined, what is to be the role of expectations and in which longitudinal data are available for empirical verification. If we consider, in addition to fertility and labour force participation, education, occupational choice etc. also as jointly endogenous, there is little left to act as exogenous variables and the model equations are likely to become underidentified. As in other areas of economics, the choice of exogenous variables in the economics of fertility and labour supply depends on the specific research questions and the limitations of the available data. When we consider a period analysis in which at a certain point in time the number of children gained in the past and any previous involvement in the labour market is given, the effect of the presence of children on labour supply will be stronger than the effect of labour supply on fertility. Family size can not be adjusted downwards, but labour supply is relatively flexible (Montgomery and Trussell, 1986, p.259). This explains, as noted earlier, that the presence of children is more likely to affect labour supply than vice versa.

\section{Conclusions}

In this paper we focussed on the regional variation in female labour force participation rates and fertility in New Zealand. We showed that the average level of fertility and the average female labour force participation rate in a region are both influenced, but in opposite ways, by the hourly wage of females and the annual income of males. The composition of the population in the region and the regional labour market also play a role. During the 197686 decade, female labour force participation and fertility became less responsive to changes in male income and the female hourly wage. Suggested reasons are sharply rising female labour force participation, a decline in the Total Fertility Rate, a greater time input of males in non-market work, changes in the home production technology and changes in societal values.

\section{Future Research}

Further work on the relationship between fertility and female labour force participation would benefit from a more disaggregated approach. Trends in cohabitation, divorce and single parenthood have made family structures more complex and this is likely to impact on fertility and labour supply decisions. Unfortunately, there is a lack of statistical information in this area in New Zealand. Ideally, longitudinal survey data would permit the testing of a response of fertility to changing labour market conditions and, vice versa, the impact of an increase in family size on labour supply. Even suitable single-date surveys, such as the Australian one used by Miller (1988) to test economic models of fertility are not available. However, an in-depth study of labour supply and fertility using 1991 census data, with the household as the observational unit, would be of interest. Such a study could either adopt the approach of Harris (1992) of using high-dimensional cross-tabulated data or, if the proposed statistical laboratory at the Department of Statistics goes ahead, researchers could make use of unit record data.

There are also sources of data which have not yet been exploited to the full extent for an econometric analysis of labour market issues. For example the Household Labour Force Survey would become a very promising research tool in this context if information on wages and salaries would be included. Of interest is also the pilot survey of time use referred to earlier. A substantive time-use survey would be feasible and desirable.

In addition, at least three important questions for research come to mind. The first is the possible relationship between rise in the TFR in recent years and a declining female labour force participation. The common explanation is in terms of demographic causes (age-cohort effects and changes in the timing and spacing of childbirth), but a labour market influence should not be entirely dismissed. A second issue is the possible link between fertility changes and actual (or anticipated) social policy changes, such as regarding the availability of public pensions. Finally, the role of formal and informal means of childcare on labour market decisions and desired family size is also an important topic for further research.

\section{References}

Becker, G.S. 1960 An Economic Analysis of Fertility in: Demographic and Economic Change in Developed Countries NBER Princeton NJ.

Becker, G.S. 1965 A Theory of the Allocation of Time Economic Journal 75: 493-517.

Becker, G.S. 1981 A Treatise on the Family Harvard University Press Cambridge Mass.

Becker, G.S. and Barro, R.J. 1988 A Reformulation of the Economic Theory of Fertility Quarterly Journal of Economics $1031: 1-25$.

Biddle, J.E. and Hamermesh, D.S. 1990 Sleep and the Allocation of Time Journal of Political Economy $985:$ : 922-943.

Brooks, R. 1991 Male and Female Labour Force Participation in New Zealand 1965-1990: A Cointegration Analysis New Zealand Economic Papers $252: 21251$. 
Browning, M. 1992 Children and Household Economic Behaviour Journal of Economic Literature 303 : 1434-1475.

Cigno, A. 1991 Economics of the Family Clarendon Press Oxford.

Cleland, J. and Wilson, C. 1987 Demand Theories of the Fertility Transition: An Iconoclastic View Population Studies 41: 5-30.

Department of Statistics, 1982 Regional Summary New Zealand Census of Population and Dwellings 1981 Regional Statistics Series Bulletin 10 Wellington.

Department of Statistics, 1987 Regional Summary New Zealand Census of Population and Dwellings 1986 Series B Report 24 Wellington.

Department of Statistics, 1989 Demographic Trends 1988 Wellington.

Department of Statistics, 1991 Testing Time Wellington.

Easterlin, R.A. Pollak, R.A. and M.L.Wachter 1980 Towards a More General Economic Model of Fertility Determination: Endogenous Preferences and Natural Fertility. In: R.A. Easterlin ed. Population and Economic Change in Developing Countries University of Chicago Press Chicago.

Ehrlich, I. and Lui, F.T. 1991 Intergenerational Trade Longevity and Economic Growth Journal of Political Economy 995 : 1029-1059.

Harris, R. and Raney, L. 1991 Participation and the Supply of Hours for New Zealand Females in 1986: Differences across Ethnic Groups in: J. Whitwell and M.A. Thompson eds. Society and Culture: Economic Perspectives New Zealand Association of Economists Wellington.

Harris, R. 1992 Ethnicity, Gender and Labour Supply in New Zealand 1986 New Zealand Economic Papers 26(2):199-218

Hockey, R.L.and Khawaja, M.A. 1984 Sub-National Differentials in New Zealand Fertility 1976: Regression Analyses Demographic Bulletin 51 Department of Statistics 5-30.

Hyman, P. 1979 Inter-Urban Variation in Female Labour Force Participation in New Zealand 1971 New Zealand Economic Papers 13: 115-139.

Hyman, P. 1992a Pay Equity Developments in Five Countries - What Can We Learn From the Different Approaches? Victoria Economic Commentaries $92: 15-26$.
Hyman, P. 1992b The Use of Economic Orthodoxy to Justify Inequality: A Feminist Critique. In: R. Du Plessis et al. eds. Feminist Voices: a Women's Studies Text for Aotearoa Oxford University Press Auckland.

Juster, F.T. and Stafford, F.P. 1991 The Allocation of Time: Empirical Findings Behavioral Models and Problems of Measurement Journal of Economic Literature 242 : 471-522.

Lowe, R.J. 1983 Regional Community Profiles 1976 Technical Report No. 16 Town and Country Planning Directorate Ministry of Works and Development Wellington.

Lowe, R.J. 1988 Abstract of New Zealand Regional Statistics Department of Statistics Wellington.

Michael, R.T. 1974 Education and the Derived Demand for Children in: T.W. Schultz ed. The Economics of the Family University of ChicagoPress Chicago 120-156.

Miller,P.W. 1988Economic models of fertility behaviour in Australia Australian Economic Papers, 27 (5): 65-82

Mincer, J. 1962 Labor Force Participation of Married Women: A Study of Labor Supply in: H.G. Lewis ed. Aspects of Labor Economics Princeton.

Montgomery, M. and Trussell, J. 1986 Models of Marital Status and Childbearing in: $O$. Ashenfelter and R. Layard eds. Handbook of Labor Economics North-Holland Amsterdam.

Pool, I. 1991 Te Iwi Maori: A New Zealand Population Past Present and Projected Auckland University Press Auckland.

Pool, I. 1992 The New Zealand Family: Structural Changes in the Context of Shifts in Societal Values New Zealand Population Review 18(1\&2): 69-87

Poot , J. 1988 The New Zealand Labour Force: A Demographi Outlook in: C. Crothers and R.D. Bedford eds. The Business of Population New Zealand Demographic Society Wellington 91106.

Poot, J. and Siegers, J.J. 1992 An Economic Analysis of Fertility and Female Labour Force Participation in New Zealand New Zealand Economic Papers 262 219-248.

Population Monitoring Group 1989 Diversity and Change: Regional Populations in New Zealand PMG Report No. 5 New Zealand Planning Council Wellington. 
Rankin, K. 1991 New Zealand's Labour Supply in a Long-Term Perspective in: L. Evans J. Poot and N. Quigley eds. Long-Run Perspectives on the New Zealand Economy New Zealand Association of Economists Wellington.

Revell, P.M. and Brosnan, P. 1986 New Zealand Labour Force Participation: the Ninety Years to 1981 New Zealand Journal of Industrial Relations 11: 77-89.

Ross, R.T. 1987 Disaggregate Labour Supply Functions for Married Women in New Zealand New Zealand Economic Papers 21: 41-56.

Schultz, T.P. 1969 An Economic Model of Family Planning andFertility Journal of Political Economy 77: 153-180.

Schultz, T.P. 1981 Economics of Population AddisonWesley Reading Mass.

Schultz, T.W. 1974 The Economics of the Family University of Chicago Press Chicago.

Simon, J.L. 1974 The Effects of Income on Fertility Chapel Hill N.C.

Tzannatos, Z. and Symons, J. 1989 An Economic Approach to Fertility in Britain Since 1860 Journal of Population Economics 2: 121-138.

Van Mourik, A. Poot J.and JJ.Siegers 1989 Trends in Occupational Segregation of Women and Men in New Zealand New Zealand Economic Papers 23: 29-50. 